Portland State University

PDXScholar

Psychology Faculty Publications and

Presentations

Psychology

4-2014

\title{
Racial Bias in Driver Yielding Behavior at Crosswalks
}

Tara Goddard

Portland State University

Kimberly Barsamian Kahn

Portland State University, kimbkahn@pdx.edu

Arlie Adkins

University of Arizona

Follow this and additional works at: https://pdxscholar.library.pdx.edu/psy_fac

Part of the Experimental Analysis of Behavior Commons, and the Race and Ethnicity Commons Let us know how access to this document benefits you.

\section{Citation Details}

Goddard, Tara, Kimberly Barsamian Kahn and Arlie Adkins. Racial Bias in Driver Yielding Behavior at Crosswalks. NITC-SS-733. Portland, OR: Transportation Research and Education Center (TREC), 2014. http://dx.doi.org/10.15760/trec.130

This Report is brought to you for free and open access. It has been accepted for inclusion in Psychology Faculty Publications and Presentations by an authorized administrator of PDXScholar. Please contact us if we can make this document more accessible: pdxscholar@pdx.edu. 


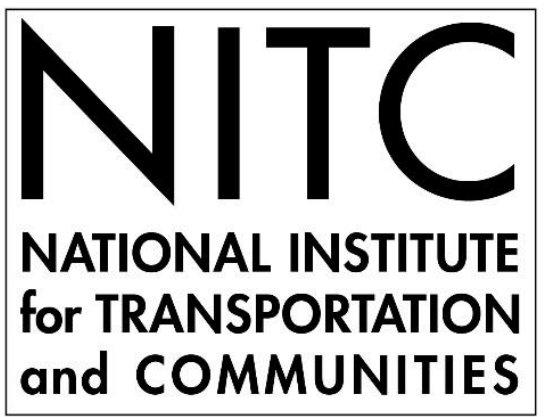

FINAL REPORT

\section{Racial Bias in Driver Yielding Behavior at Crosswalks}

NITC-SS-733

April 2014 



\title{
Racial Bias in Driver Yielding Behavior at Crosswalks
}

\author{
Tara Goddard ${ }^{\mathrm{a}}$, Kimberly Barsamian Kahn ${ }^{\mathrm{b}},{ }^{\mathrm{a}, \mathrm{b}}$ Portland State University, Portland, \\ Oregon, USA, Arlie Adkins ${ }^{\mathrm{c}}$, ${ }^{\mathrm{U}}$ University of Arizona, Tucson, Arizona, USA
}

Keywords: racial bias; discrimination, pedestrian safety; intermodal conflict

\section{CORRESPONDING AUTHOR:}

Tara Goddard

Portland State University

Toulan School of Urban Studies and Planning

PO Box 751-USP

Portland, OR, USA 97207-0751

goddard@pdx.edu

\section{DECLARATION OF CONFLICT OF INTEREST:}

The authors declared no potential conflicts of interests with respect to the authorship and/or publication of this article.

\section{FINANCIAL DISCLOSURE/FUNDING:}

The author(s) disclosed receipt of the following financial support for the research and/or authorship of this article: This project was funded by a National Institute for Transportation and Communities (NITC) "Small Starts" grant. The grant is part of the University Transportation Center (UTC) program funded by the U.S. Department of Transportation's Research and Innovative Technology Administration (RITA). 


\title{
Racial Bias in Driver Yielding Behavior at Crosswalks
}

\begin{abstract}
:
Racial minorities are disproportionately represented in pedestrian traffic fatalities, indicating a significant public health and safety issue. Psychological and social identity-related factors have previously been shown to influence drivers' behaviors toward pedestrians. If drivers' behavior reflects racial bias and results in differential behavior toward Black and White pedestrians, this may lead to disparate pedestrian crossing experiences based on race and potentially contribute to disproportionate safety outcomes. We tested this hypothesis in a controlled field experiment at an unsignalized midblock marked crosswalk in downtown Portland, Oregon. Six trained male research team confederates ( 3 White, 3 Black) simulated an individual pedestrian crossing, while trained observers cataloged the number of cars that passed and the time until a driver yielded. Results (90 pedestrian trials, 168 driver-subjects) revealed that Black pedestrians were passed by twice as many cars and experienced wait times that were $32 \%$ longer than White pedestrians. Results support the hypothesis that minority pedestrians experience discriminatory treatment by drivers.
\end{abstract}




\section{Introduction}

In the United States, racial minorities are disproportionately represented in pedestrian fatalities. From 2000 to 2010, the pedestrian fatality rates for Black and Hispanic men (3.93 and 3.73 per 100,000 population) were twice the rate for White men (1.78), according to the Centers for Disease Control and Prevention (2013). Minority pedestrians are more likely to be killed in a motor vehicle crash even after controlling for increased traffic exposure in urban areas, socioeconomic status, and alcohol use (CDC, 2013). One potential and unexplored contributing factor to these disparate outcomes is whether driver behavior differs toward pedestrians by race. Similar to other types of intergroup interactions, roadway interactions between drivers and pedestrians are likely influenced by drivers' subtle racial attitudes and biases.

The current study focuses on pedestrians' street crossings, as pedestrians are most vulnerable when crossing traffic lanes. According to the National Highway Traffic Safety Administration, 60 percent or more of pedestrian fatalities occur during street crossings (NHTSA, 2003). Marked crosswalks at unsignalized intersections or at midblock draw drivers' attention to the possible presence of crossing pedestrians; however, they have also been shown to give pedestrians a false sense of safety that may increase risk exposure (Zegeer, 2005).

Understanding driver-pedestrian interactions at crosswalks is therefore key to addressing the public safety issues that result from the shared use of road space.

This research investigates whether driver behavior toward pedestrians in crosswalks is influenced by the race of the crossing pedestrian. We utilized a controlled field experiment in which we observed how drivers' stopping behavior differed depending on whether a White or Black pedestrian (trained members of the research team) was attempting to cross at a marked crosswalk. Results are based on analysis of whether the first approaching car stopped, how many 
cars passed before the confederate could cross, and the time a pedestrian had to wait before crossing. We hypothesized that drivers are less likely to stop for Black pedestrians than for White pedestrians crossing at a marked crosswalk and that Black pedestrians have longer wait times before they can safely cross. Differences in minority pedestrians' experiences at crosswalks may lead to more delay, increased risk, and lower quality pedestrian experiences, leading minority pedestrians to adopt unsafe crossing behaviors and dissuading them from choosing active transportation modes. These findings have implications for crosswalk design and may help inform efforts to promote equitable access to active transportation within minority communities.

\subsection{The role of social identity characteristics in driver-pedestrian interactions}

Drivers do not treat all pedestrians the same on the road. Different social identity characteristics of both the driver and pedestrian have been shown to influence drivers' yielding behavior at crosswalks. Visibly identifying some pedestrians as disabled by equipping them with a cane resulted in more frequent driver yielding, fewer cars passing without yielding, and shorter wait times (Harrell, 1992). In a study of Israeli drivers, drivers were more likely to yield to pedestrians in their own age group (Rosenbloom, Nemrodov, \& Ben, 2006). Driver's socioeconomic status, indicated by vehicle type, influenced whether a driver would yield to pedestrians, with drivers of high-status cars less likely to yield to pedestrians (Piff, Stancato, Mendoza-Denton, Keltner, \& Coteb, 2012). These results suggest that drivers' perceive yielding to pedestrians as a courtesy or granting of privilege, rather than an observance of rights as is often the case by law. This perceived discretionary choice may be differentially made depending on the social identity of pedestrians. 
The current experiment tests whether racial group membership is one such social identity that influences drivers' stopping behavior for pedestrians. Racial minorities are subjected to racially biased treatment and outcomes across a variety of societal domains, including education (Steele, 2010), employment (Pager, 2003; Schwartzman, 1997; Wilson, 1996), health care (Budrys, 2010; Dovidio, Penner, Albrecht, Norton, Gaertner, \& Shelton, 2008), and criminal sentencing (Blair \& Chapleau, 2004; Eberhardt, Davies, Purdie-Vaughns, \& Johnson, 2006). Racially-biased behaviors are also reflected in interpersonal interracial interactions, as subtle stereotypes influence individuals' judgments and decisions (Dovidio, Kawakami, \& Gaertner, 2002; Richeson \& Shelton, 2007). We posited that racially biased treatment is also reflected in intermodal interactions within the transportation arena, particularly in driver's behavior toward pedestrians.

If drivers demonstrate racially-biased behaviors, these behaviors may reflect implicit racial attitudes. While explicitly (conscious and freely expressed forms of racial bias) biased attitudes have decreased over the last 50 years (Bobo, 1991), contemporary forms of racial bias are often demonstrated on a covert or implicit level (Dovidio, 2001; Greenwald \& Banaji, 1995; Greenwald, Poehlman, Uhlmann, \& Banaji, 2009; Olson \& Fazio, 2003). Implicit racial biases are subtle, biased beliefs that individuals hold beneath their conscious awareness, but that can lead to discriminatory behavior and outcomes. Pro-White, Anti-Black implicit attitudes are commonly held by a large percentage of Americans and have been shown to be a cause of discriminatory outcomes against minorities in society (Greenwald \& Banaji, 1995; Banaji \& Greenwald, 2013, see also Project Implicit). Implicit bias influences decisions that are harder to monitor and more difficult to control, and are particularly influential in fast paced situations. Implicit bias has been shown to affect split-second decisions regarding safety-related behavior, 
exposing minorities to more dangerous outcomes than majority group members (Kahn \& Davies, 2011). Driving behaviors are likely influenced by driver's implicit attitudes, as driving and stopping decisions are often fast paced, rife with distractions, and consciously or sub-consciously initiated. The result of this process may be differential stopping behavior based on pedestrian race.

\section{Methods}

\subsection{Subjects and Design}

The field experiment was a one-way between-subjects design, with pedestrian race (Black vs. White) as the independent variable. Data were collected on 90 individual pedestrian crossing trials involving three White and three Black research confederates. Pedestrians crossed the street using a marked crosswalk on a busy two-lane, one-way street in downtown Portland,

Oregon. Each research confederate pedestrian completed 15 crossing trials. These trials resulted in 168 driver subjects.

\subsection{Location and time}

Trials were conducted over five days in September, October, and November 2013, with mild weather and clear conditions. All trials took place in off-peak hours of the morning and afternoon, under free-flow traffic conditions (i.e., no stop-and-go or congested traffic). Trials were initiated when no other pedestrians were present. If additional pedestrians arrived at the crosswalk while a trial was underway, data collection continued but these trials were excluded from the current analysis. In the final analysis, two trials were removed due to missing data. Final trials included for analysis were evenly distributed by time of day and individual field session. The pattern of results does not differ based on crossing session. 
The experiment was conducted at an unsignalized midblock crosswalk in downtown Portland, Oregon. Downtown Portland has short block lengths and is laid out in the grid pattern typical of urban downtowns. The study crosswalk is marked with the common "zebra" pattern and connects two of the Portland "park blocks" at midblock. This area is a busy pedestrian environment near Portland State University, where drivers frequently encounter pedestrians during daytime hours. Pilot testing confirmed that sight distances at the crosswalk allowed drivers to see the waiting pedestrians with sufficient time to safely stop. Traffic travels one-way from east to west in two lanes. Using a midblock crossing reduced the complication of turning movements affecting drivers' propensity to stop for pedestrians and reduced ambiguity about whether a driver was slowing to yield for the pedestrian or to make a turn.

\subsection{Experimental Procedure}

Three White and three Black research confederates were recruited to participate in the study as the crossing pedestrians. All six were men in their 20s, and were matched based on their height and build. The confederate pedestrians wore an identical outfit of long-sleeve gray tshirt and khaki pants to achieve a neutrally-colored palette that did not indicate any obvious socio-economic status or social characteristics.

Members of the research team served as coders and observers. Two trained observers stood approximately 30 feet from the crosswalk (out of sight of oncoming cars) and recorded whether the first car to approach yielded to the pedestrian, how many cars passed by before a driver yielded, and how many seconds elapsed before each pedestrian was able to cross (from time the pedestrian stepped up to edge of the curb until when the driver yielded to the pedestrian to cross). Inter rater reliability ranged from 0.9 to 1.0 on all measures. Video recordings of the crossings were used to confirm and further analyze observations made in the field. 
The pedestrian crossing trials began at the signal of a research team member. The pedestrians waited as a group out of sight of the cars and approached the crosswalk one at a time when instructed. The three White and three Black research confederates took alternating turns crossing the street. Confederates were cued so that they arrived at the crosswalk at the same time when the first set of cars passed a marked spot, approximately 300 feet away, after being stopped at a stop light. Confederates indicated their intention to cross by stepping up to the curb, positioning their body slightly toward oncoming traffic, making eye contact if possible, and remaining on the curb until a driver clearly yielded. Oregon law requires that a driver must stop only after a pedestrian has stepped into a marked crosswalk. Our experiment was not testing compliance with the law, but rather the extension of courtesy to pedestrians who were clearly waiting to cross the street but had not yet entered the roadway.

Once a car had clearly yielded or stopped for the pedestrian, the timing variable stopped and the pedestrian crossed the street at a normal walking pace. When the pedestrian reached the other side of the road, the trial ended. There was approximately a one- to two-minute break before the next pedestrian was cued to approach the crosswalk and begin the subsequent trial.

\section{Results}

Differences between driver stopping behaviors toward Black and White pedestrians were examined for three variables of interest: number of cars that passed without yielding, elapsed time before pedestrian could cross, and a dichotomous variable indicating whether the first approaching car stopped after the pedestrian approached the curb. 


\subsection{Descriptive statistics}

A total of 168 drivers passed through the crosswalk during the 88 included trials. The first car to approach stopped in roughly half (52.3\%) of the trials. The average number of cars to pass was $1.49(\mathrm{SD}=2.07)$, and the average wait until a car yielded was 8.57 seconds ( $\mathrm{SD}=4.97)$.

\subsection{Differences in driver behavior toward pedestrians by race}

3.2.1 Number of cars passing without yielding. As hypothesized, results from a one way ANOVA on number of cars that passed without yielding significantly differed by the race of the pedestrian, with Black pedestrians waiting for more cars to pass than White pedestrians, $F(1,87)=5.95, \mathrm{p}=.017, \eta^{2}=.065$, see Figure 1. The average of 2.02 drivers $(\mathrm{SD}=2.39)$ that passed Black pedestrians without stopping was more than twice the average of .98 drivers ( $\mathrm{SD}=1.56)$ who passed White pedestrians without stopping.

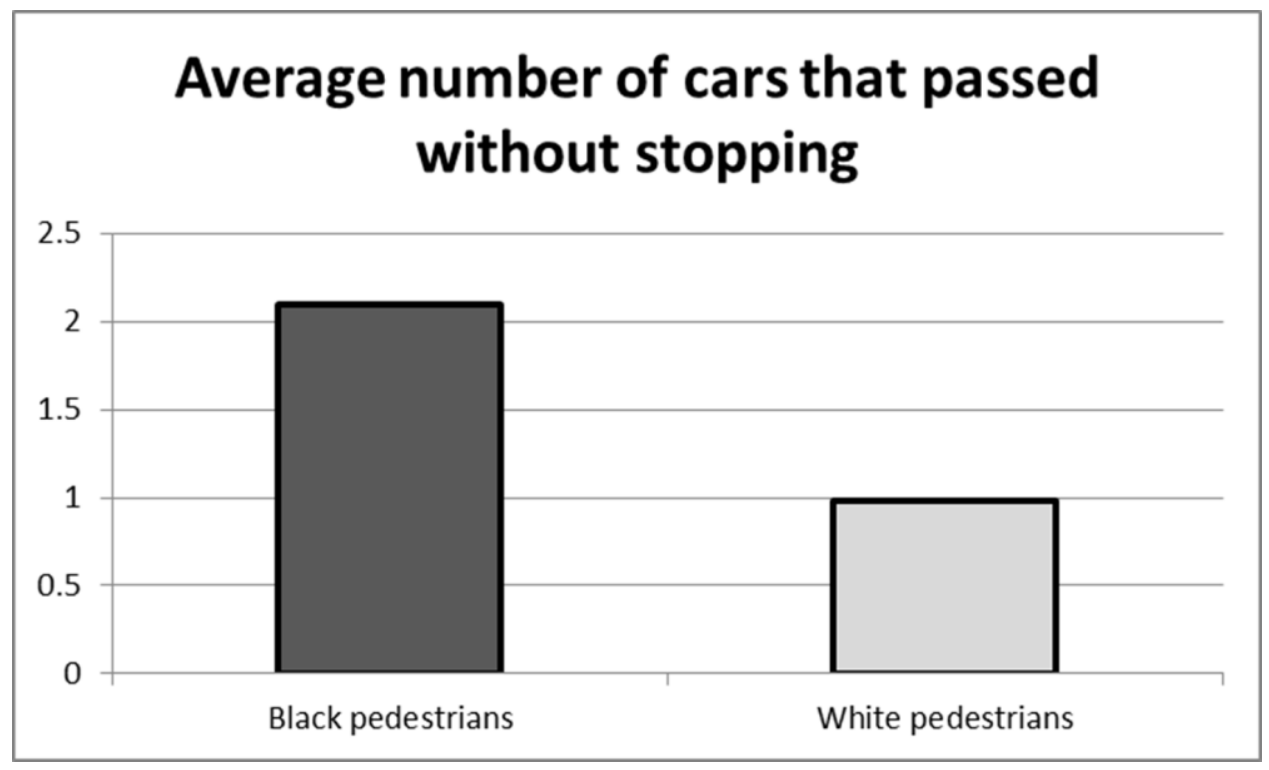

Figure 1. Number of cars that passed before pedestrian could cross (by pedestrian race) 
3.2.2 Time until yield. A one way ANOVA on time until yield varied significantly by pedestrian race, $F(1,87)=5.31, \mathrm{p}=.024, \eta^{2}=.058$, see Figure 2 . The average wait time until yield of $9.79(\mathrm{SD}=5.67)$ seconds for Black pedestrians was $32 \%$ longer than the $7.40(\mathrm{SD}=3.93)$ seconds for White pedestrians.

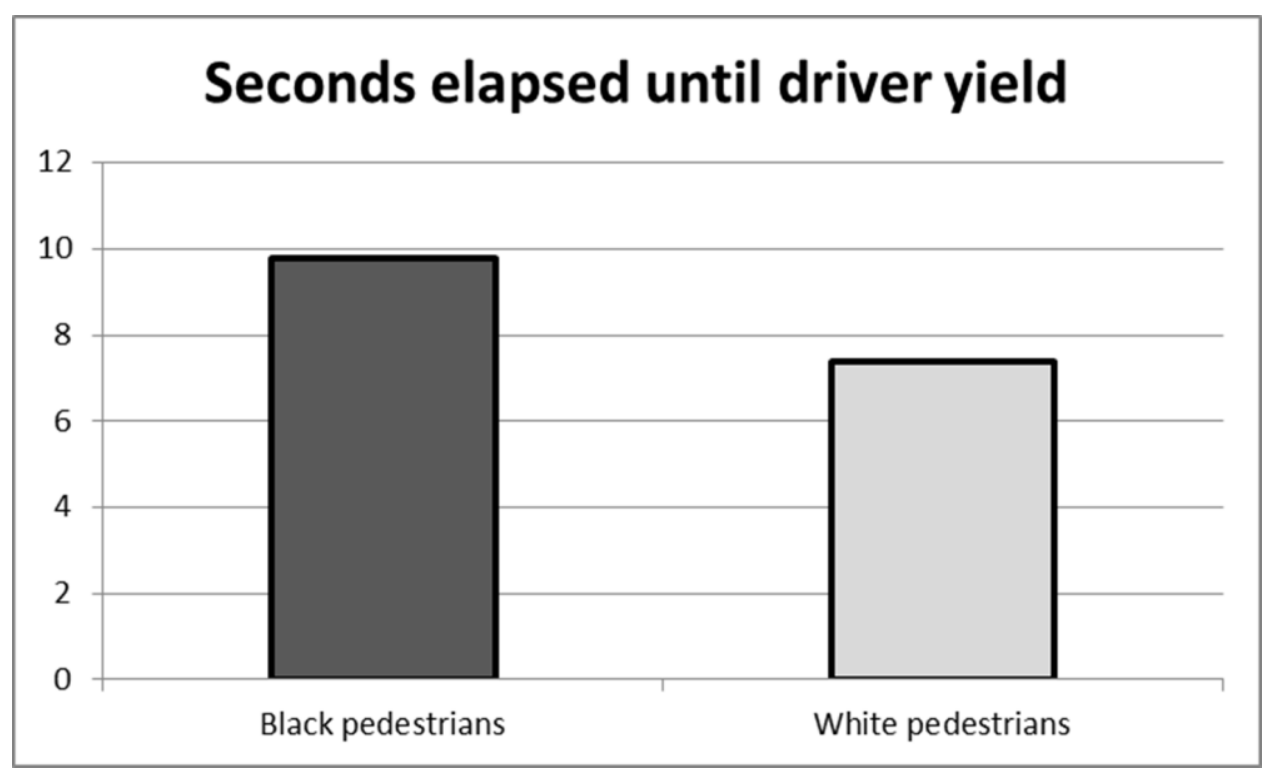

Figure 2.Overall time elapsed before pedestrian could cross (by pedestrian race) 
3.2.3 First car stopping. Although in the predicted direction, a chi-squared test indicated that whether the first car stopped did not significantly differ by pedestrian race, $\chi^{2}=.398, p=.528$, (55.6\% of first cars stopped for White pedestrians vs. $48.8 \%$ for Black pedestrians), see Figure 3. Black pedestrians were, however, more than twice as likely as White pedestrians $(45.2 \%$ versus $22.2 \%)$ to have to wait for two or more cars, $\chi^{2}=5.18, \mathrm{p} .=.02, \Phi=.244$.

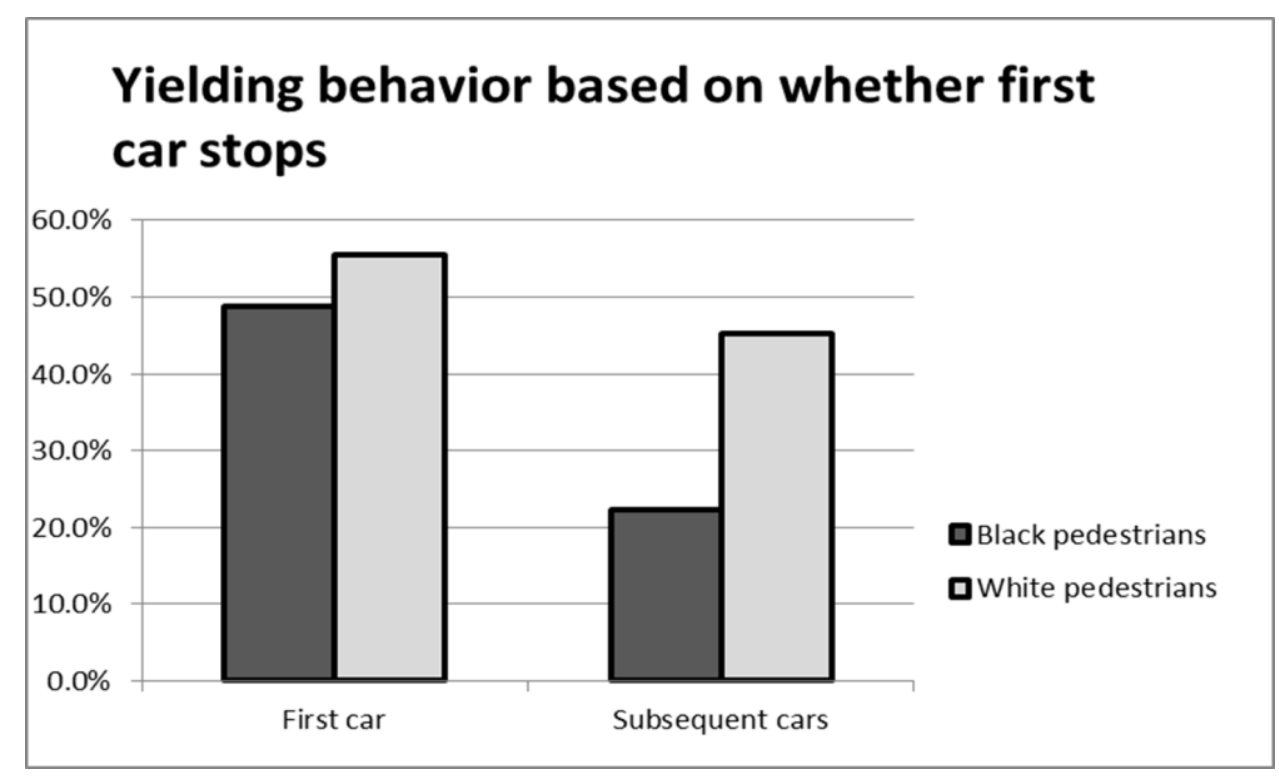

Figure 3. Yielding behavior by pedestrian race depending on whether first car stops

\section{Discussion}

In this controlled field experiment, drivers were less likely to stop for Black pedestrians than for White pedestrians. Correspondingly, Black pedestrians experienced significantly longer waiting times to cross the street safely. The controlled experimental methodology used in the field experiment indicates the causal nature of pedestrian race on drivers' stopping behavior. While the overall difference in wait times may appear small on the surface, the cumulative differences grow in magnitude if these longer wait times are projected across multiple street crossings on an average walk. The moderate effect sizes also suggest that these differences may 
have a significant impact on daily walking experiences. As wait time increases and cars continue to pass, minority pedestrians may experience substantial inconvenience and discomfort.

Drivers refusing to stop may be viewed by minority pedestrians as an aggressive act, and seems discourteous at best. These negative acts may be perceived as examples of microaggressions — small and commonplace verbal, behavioral, or environmental experiences that indicate negative racial treatment (Hebl, Foster, Mannix, \& Dividio, 2002; Sue, Capodilupo, \& Holder, 2008; Singletary \& Hebl, 2009). Similar to other forms of microaggressions, the additive effect of routine inconveniences such as the additional delay at crosswalks observed in our study can, over time, add up to significant burdens for racial minorities. Repeated negative experiences while crossing may discourage them from choosing to walk or put them in unnecessary danger if they attempt to force right-of-way compliance by cars. If minorities attempt to cross in unsafe conditions, this behavior may partially explain the disproportionality of minority victims in pedestrian deaths.

Because this was a naturalistic field experiment in which drivers were unaware they were being observed, we are not able to make conclusions about the source of the racial bias of drivers. It is possible, although less likely, that drivers were consciously, overtly, and explicitly racially biased in their stopping decisions, deliberately deciding to not stop for Black pedestrians. Our findings are, however, more consistent with behavioral manifestations of implicit racial attitudes (e.g., Greenwald \& Banaji, 1995; Greenwald, Nosek, \& Banaji, 2003; Greenwald, Poehlman, Uhlmann, \& Banaji, 2009; Nosek, Greenwald, \& Banaji, 2005). Implicit attitudes are more predictive of behavior when situations necessitate quick decision making, distractions are present, and anonymity is increased (e.g., Kahn \& Davies, 2011), as exists when driving on a busy street. Because implicit racial bias against Blacks is a commonly held attitude (e.g., 
Greenwald \& Banaji, 1995), drivers' implicit racial attitudes might explain the biased stopping behavior as they make quick decisions while scanning the road and evaluating multiple stimuli. Also characteristic of implicit bias, drivers may be less aware of the discrimination that results from their biased stopping decisions. The lack of awareness of implicit racial bias allows these biases to magnify and persist. Future research should experimentally clarify the causal role of implicit or explicit racial attitudes on driver's stopping decisions using other methodologies, including driving simulators. Illuminating the psychological processes through which drivers make these biased stopping decisions would inform potential intervention routes.

Perceived social norms may also influence drivers' differential stopping behavior by pedestrian race. The discrepancy in drivers' yielding behavior toward Black and White pedestrians was greater for subsequent drivers if the first driver did not stop. The longer waits faced by Black pedestrians may result from drivers observing the behavior of vehicles preceding them and replicating this behavior. That is, they may observe other drivers not stopping for Black pedestrians and use this evidence to inform or even justify their decisions to not stop. This pattern is consistent with the Focus Theory of Normative Conduct, which states that people are more likely to perform anti-social behavior if their focus is drawn to a normative example of that anti-social behavior (Cialdini, Reno, \& Kallgren, 1990). Further investigation of the role of descriptive social norms can be used to more fully understand the role of normative conduct in driver yielding behavior by pedestrian race. 


\section{Conclusion}

Our findings raise practical questions for transportation planners and engineers aiming to increase minority participation in active transportation modes such as walking and bicycling. Changing racial biases, particularly implicit ones, is a difficult task. Interventions such as pedestrian-activated signals that explicitly make stopping a mandatory act rather than a discretionary act may reduce observed behavioral discrepancies by pedestrian race. Further investigation of racial bias in driver-pedestrian interactions could shed light on whether other design features, such as curb extensions or posted signage, could mitigate the influence of drivers' racial biases. These changes may encourage more minorities to use healthy transportation modes. Decreasing the racial bias in drivers' stopping behavior will lead to more equitable transportation experiences for all pedestrians and improve public safety. 


\section{References:}

Banaji, M. R., \& Greenwald, A. G. (2013). Blindspot: Hidden biases of good people. Random House LLC.

Blair, I.V., Judd, C. M., \& Chapleau, K.M. (2004a). The influence of Afrocentric facial features in criminal sentencing. Psychological Science, 15, 674-679.

Bobo, L. (2001). Racial attitudes and relations at the close of the twentieth century. In N. J. Smelser,W. J.Wilson, \& F. Mitchell (Eds.), Racial trends and their consequences, Vol. 1 (pp. 264-301). Washington, DC: National Academy Press.

Budrys, G. (2010). Unequal health: How inequality contributes to health or illness. Lanham, MD: Rowman \& Littlefield Publishers, Inc.

Cialdini, R. B., Reno, R. R., \& Kallgren, C. A. (1990). A focus theory of normative conduct: Recycling the concept of norms to reduce littering in public places. Journal of Personality and Social Psychology, 58, 6, 1015-1026.

Dovidio, J. F. (2001). On the Nature of Contemporary Prejudice: The Third Wave. Journal of Social Issues, 57, 4, 829-849.

Dovidio, J. F., Kawakami, K., \& Gaertner, S. L. (2002). Implicit and explicit prejudice and interracial interaction. Journal of Personality and Social Psychology, 82, 62-68.

Dovidio, J. F., Penner, L. A., Albrecht, T. L., Norton, W. E., Gaertner, S. L., \& Shelton, J. N. (2008). Disparities and distrust: the implications of psychological processes for understanding racial disparities in health and health care. Social Science \& Medicine, 67, 478-486.

Eberhardt, J.L., Davies, P.G., Purdie-Vaughns, V.J., \& Johnson, S.L. (2006). Looking deathworthy: Perceived stereotypicality of Black defendants predicts capital-sentencing outcomes. Psychological Science, 17, 383-386.

Greenwald, A. G., \& Banaji, M. R. (1995). Implicit social cognition: attitudes, self-esteem, and stereotypes. Psychological Review, 102, 1, 4-27.

Greenwald, A. G., Nosek, B. A., \& Banaji, M. R. (2003). Understanding and using the implicit association test: I. An improved scoring algorithm. Journal of Personality and Social Psychology, 85, 2, 197-216.

Greenwald, A. G., Poehlman, T. A., Uhlmann, E. L., \& Banaji, M. R. (2009). Understanding and using the Implicit Association Test: III. Meta-analysis of predictive validity. Journal of Personality and Social Psychology, 97, 1, 17-41.

Harrell, W. A. (1992). Driver Response to a Disabled Pedestrian Using a Dangerous Crosswalk. Journal of Environmental Psychology, 12, 4, 345.

Harrell, W. A. (1993). The Impact of Pedestrian Visibility and Assertiveness on Motorist Yielding. Journal of Social Psychology, 133, 3.)

Hebl, M. R., Foster, J. B., Mannix, L. M., \& Dovidio, J. F. (2002). Formal and Interpersonal Discrimination: A Field Study of Bias Toward Homosexual Applicants. Personality and Social Psychology Bulletin, 28, 6, 815-825.

Huybers, S., Van, H. R., \& Malenfant, J. E. (2004). Reducing conflicts between motor vehicles and pedestrians: The separate and combined effects of pavement markings and a sign prompt. Journal of Applied Behavior Analysis, 37, 4, 445-56. 
Kahn, K., \& Davies, P. (2011). Differentially dangerous? Phenotypic racial stereotypicality increases implicit bias among ingroup and outgroup members. Group Processes and Intergroup Relations, 14, 4, 569-580.

National Highway Traffic Safety Administration. (2003). Pedestrian roadway fatalities. Annals of Emergency Medicine, 42, 4, 479-80.

National Highway Traffic Safety Administration. (2009). Traffic safety facts, 2006 data: race and ethnicity. Washington, DC. Available at http://wwwnrd.nhtsa.dot.gov/pubs/810995.pdf

Nosek, B. A., Greenwald, A. G., \& Banaji, M. R. (2005). Understanding and using the Implicit Association Test: II. Method variables and construct validity. Personality \& Social Psychology Bulletin, 31, 2, 166-80.

Olson, M. A., \& Fazio, R. H. (2003). Relations between implicit measures of prejudice: What are we measuring? Psychological Science, 14, 6, 636-639.

Pager, D. (2003). The Mark of a Criminal Record. American Journal of Sociology, 108, 937975.

Piff, P. K., Stancato, D. M., Mendoza-Denton, R., Keltner, D., \& Coteb, S. (2012). Higher social class predicts increased unethical behavior. Proceedings of the National Academy of Sciences of the United States of America, 109, 11, 4086-4091.

Project Implicit. Retrieved September 2, 2013 from www.projectimplicit.net

Richeson, J. A., \& Shelton, J. N. (2007). Negotiating interracial interactions costs, consequences, and possibilities. Current Directions in Psychological Science, 16, 316-320.

Rosenbloom, T., Nemrodov, D., \& Ben, E. A. (2006). Yielding behavior of Israeli drivers: interaction of age and sex. Perceptual and Motor Skills, 103, 2, 387-90.

Schwartzman, D. (1997). Black male unemployment. The Review of Black Political Economy, 25, 77-93.

Singletary, S. L., \& Hebl, M. R. (2009). Compensatory strategies for reducing interpersonal discrimination: the effectiveness of acknowledgments, increased positivity, and individuating information. The Journal of Applied Psychology, 94, 3, 797-805.

Steele, C. M. (2010). Whistling Vivaldi and other clues to how stereotypes affect us. NewYork: W. W. Norton \& Company.

Sue, D. W., Capodilupo, C. M., \& Holder, A. (2008). Racial microaggressions in the life experience of Black Americans. Professional Psychology: Research and Practice, 39, 329.

Surface Transportation Policy Partnership (2002). Mean Streets 2002. Washington, DC. Available at http://www.transact.org/PDFs/ms2002/MeanStreets2002.pdf.

Wilson, W. J. (1996). When work disappears: The world of the new urban poor. New York: Alfred Knopf.

Zegeer, C. V., United States., University of North Carolina \& Turner-Fairbank Highway Research Center. (2005). Safety effects of marked versus unmarked crosswalks at uncontrolled locations: Final report and recommended guidelines. McLean, VA: U. S. Department of Transportation, Federal Highway Administration, Research, Development, and Technology, Turner-Fairbank Highway Research Center. 